\title{
Quantitative Easing and the U.S. Stock Market: A Decision Tree Analysis
}

\author{
RAMAPRASAD BHAR \\ The University of New South Wales * \\ A.G. MALLIARIS \\ Loyola University Chicago \\ MARY MALLIARIS \\ Loyola University Chicago
}

\begin{abstract}
The Financial Crisis of 2007-09 caused the U.S. economy to experience a relatively long recession from December 2007 to June 2009. Both the U.S. government and the Federal Reserve undertook expansive fiscal and monetary policies to minimize both the severity and length of the recession. Most notably, the Federal Reserve initiated three rounds of unconventional monetary policies known as Quantitative Easing. These policies were intended to reduce long-term interest rates when the short term federal funds rates had reached the zero lower bound and could not become negative. It was argued that the lowering of longer-term interest rates would help the stock market and thus the wealth of consumers. This paper investigates this hypothesis and concludes that quantitative easing has contributed to the observed increases in the stock market's significant recovery since its crash due to the financial crisis.
\end{abstract}

Keywords: Quantitative Easing, Decision Tree, Stock Market, S\&P 500 Index, 10 Year Notes

JEL Classification: C10; C45; C58; E52; E58.

\section{Introduction}

The Financial Crisis of 2007-09 caused the U.S. economy to experience a relatively long recession from December 2007 to June 2009. Both the U.S. government and the Federal Reserve undertook momentous fiscal and monetary policies to minimize both the severity and length of the recession. Most notably, the Federal Reserve initiated three rounds of

\footnotetext{
* An earlier version was presented at the Multinational Finance Society Meetings in Prague, June 30July 2, 2014. The authors are grateful to two detailed referee reports from the Review of Economic Analysis that have substantially improved and lengthened the revised paper.

(C) 2015 Ramaprasad Bhar, A.G. Malliaris and Mary Malliaris. Licensed under the Creative Commons Attribution - Noncommercial 3.0 Licence (http://creativecommons.org/licenses/bync/3.0/. Available at http: //rofea.org.
} 
unconventional monetary policies known as Quantitative Easing. These policies were intended to reduce long-term interest rates when the short term federal funds rates had reached the zero lower bound and could not become negative.

Bernanke (2012) argues that QE works via the portfolio balance channel initially proposed by Milton Friedman and James Tobin in several of their major writings. The simple logic of this channel indicates that different classes of financial assets are not perfect substitutes in portfolios formed by investors and if the Fed can purchase large quantities of a certain asset and thus influence its price and therefore its yield, such changes may, through arbitrage transactions, spread to other asset classes. If the final result of QE is the increase of long-term bond prices and the decline of yields across many asset classes the overall economy can benefit.

The benefits of QE may originate in lower yields of longer term Treasury bonds and asset backed securities but these in turn may cause additional changes in other financial variables and ultimately contribute to economic growth. Lower longer term interest rates encourage business investment, housing construction and increases in purchases of consumer durables such as cars. Furthermore, the lower cost of debt often increases the profitability of corporations and also increases private consumption by reducing the cost of consumer debt. Corporate profits along with lower discount rates encourage investors to take more risks by buying stocks, thus increasing the overall value of the stock market which in turn stimulates further consumption via the wealth effect. Because consumer spending is the major component of GDP, restoration of consumer wealth was necessary to stabilize the real economy.

It is the purpose of this paper to investigate the impact of quantitative easing on the stock market. We first give a brief overview in section 2 of the financial crisis of 2007-09 and the Great recession and then in section 3 discuss how the Fed responded to this crisis. In section 4 we offer a bibliographical review of certain important papers. After this introductory analysis we formulate our hypotheses and describe the data used in section 5 . The results are presented and discussed in section 6 and conclusions are summarized in section 7.

\section{Overview of the Financial Crisis and the Great Recession}

There are numerous exhaustive descriptions of the Global Financial Crisis of 2007-09 such as Bernanke (2015). The key characteristics of the crisis include: relatively low interest rates during the 2002-2005 period as the Fed was facing weak economic growth and low inflation during this period; a substantial foreign saving glut that contributed to lower global interest rates and strong demand for investible vehicles; a booming real estate and housing market, also described as a housing bubble that arose because of low interest rates and support from government policies that encouraged homeownership; the creation of mortgage backed securities that pooled large groups of various mortgages; the short-term financing of various 
long-term assets by both banks and shadow banks; inadequate supervision by regulators during this boom driven primarily by beliefs in market discipline; the bursting of the housing bubble; the decline in the value of collateral held by both banks and shadow banks; the need for liquidity; and finally, the bankruptcy of Lehman Brothers and the great panic that followed.

The Great Recession that began in December 2007 and extended to June 2009 caused unemployment to increase above $10 \%$ and both fiscal and monetary policies responded robustly to such deteriorating economic conditions. In particular, for our purposes, the Fed quickly reduced short- term fed funds to $.25 \%$ that is, essentially zero and initiated the first of a series of three Quantitative Easing (QE) strategies to reduce the longer-term 10-Year Treasury Note rate. The series of these QE were not planned in advance. Each QE had its own characteristics. The first one signaled the Fed's strong determination to contain the Great Recession and, it may be argued, contributed to the termination of the recession in June 2009. The second and third QE were initiated because of subpar recovery with persistent high unemployment and low inflation. Even after the termination of the third round of QE in late 2014, there was no clear evidence that the economy has returned to trend growth. In all three QE strategies, the Fed reasoned that such a reduction in longer-term rates would allow firms to save on their debt refinancing, and other things being equal, to achieve higher earnings and profits thus helping their stocks, and restoring the wealth of households that held such stocks as a driver of stabilizing the real economy.

\section{The Evolution of QE}

Lehman Brothers filed for Chapter 11 bankruptcy protection on September 15, 2008. The Fed moved rapidly to decrease the fed funds rate and provide the much needed liquidity to the banking sector. By early October, fed funds rates had declined to .25\% and have remained that low for the past 5 years; in its forward guidance the Fed has signaled that this fed fund rate may be kept that low until the end of 2014, perhaps even beyond.

During the past several decades, the fed funds rate has been the primary tool of monetary policy. However, the Fed realized, very quickly, during the period of financial panic, that when fed funds reach the zero lower bound and cannot become negative, additional tools are needed to help the financial sector stabilize and to avoid further deterioration to the real sector. Unlike the Keynesian thought that monetary policy during a liquidity trap is ineffective, the Bernanke Fed proposed that the central bank had additional tools beyond the fed funds rate. Beginning in December 2008, the Fed initiated three credit easing or quantitative easing programs known as Q1, Q2 and Q3.

Q1, Q2 and Q3 involved large scale purchases of high grade securities including agency mortgage backed securities, agency debt, and long term government bonds. Q1 was implemented during December 2008 to March 2010; Q2 took place between November 2010 
and June 2011 and Q3 started in September 2012 and ended in late 2014. This third QE3 involved the purchase of $\$ 85$ billion securities monthly, half in mortgage backed securities and the other half in 10 Year Treasury Notes. The total purchases initiated by the Fed during the past 7 years have increased its balance sheet by over 4 trillion dollars.

\section{Literature Review and our Contribution}

Numerous studies by Chen, Curdia and Ferrero (2012), Gagnon, Raskin, Remache and Sack (2011), Hamilton and Wu (2012), Li, and Wei (2013) and Swanson (2011) have investigated the impact of these large scale securities purchases on interest rates. Williams (2011) reviews several of these studies and reports that the estimated effects of QE on Treasury yields are very close, particularly when one considers the broad variety of sample periods and different econometric methods. Specifically, the estimates of the impact of QE on decreases in Treasury yields that Williams reports range between $0.15 \%$ and $0.20 \%$. Williams also explains that this drop of between $0.15 \%$ and $0.20 \%$ in longer yields is traditionally associated with a $0.75 \%$ drop in fed funds. Thus, when the Fed was constrained by the zero lower bound, its QE policies allowed it to pursue further easing equivalent to lowering the fed funds by $0.75 \%$.

It is more challenging to hypothesize how these declines in Treasury yields have helped the Fed achieve its dual mandate of maximum employemt with stable prices. As discussed in the introduction, Bernanke (2012) claims that declines in long-term interests rates of Treasury bonds work through the portfolio channel that views finanacial assets as inter-related. Thus as QE increases the price of Treasury bonds asset reallocations take place and the price of other assets is also impacted. Such portfolio changes ultimately influence the real economy but both Bernanke (2012) and Williams (2011) admit that the particular economic stages from QE to interest rates and ultimately, say to maximum employment and price stability are not precise. In other words, there is lack of clarity in the formulation of specific hypotheses about the impact of QE on the Fed's dual mandate and thus little empirical evidence that these QE purchases have had specific effects on the macroeconomy because it is very difficult to formulate and statistically to test such hypotheses.

To restate the purpose of our paper, we focus on the impact of QE on the U.S. stock market. Since there is empirical evidence that the 3 QEs have influenced the price of Treasury bonds and produced a decline in their yields, one can reason that stock prices must also have been impacted. One important parameter that determines the present value of a representative stock is the discount factor. In turn, a discount factor has both a riskless and a risk driven component. With QE influencing downwards the risk free component, one may argue that QE may make stocks more attractive. In addition to the argument of a decreasing discount factor, the liquidity provided by the Fed purchasing Treasury bonds may be channeled into stocks. Thus, the portfolio channel leads to the possibility of investors becoming more willing to 
assume higher risk and buy stocks. But lower longer term rates also increase the value of housing as well as the value of stocks, thus contributing to increases in national wealth. It is the relationship between QE and the stock market that we wish to investigate so further hypotheses about the QE and the dual mandate can be explored in the future having settled the link between $\mathrm{QE}$ and the stock market as a piece in a longer chain of dynamic consequences.

What do we know about Fed policies and the stock market? This topic has attracted numerous researchers and we have selected two important studies prior to the Global Financial Crisis and three since the introduction of QE. Bernanke and Kuttner (2005) analyze the impact of monetary policy by the Fed as represented by changes in fed funds. They show empirically that Federal Reserve policy influences the stock market. Specifically they find that on average a hypothetical unanticipated $.25 \%$ cut in the fed funds target is associated with about 1\% increase in the S\&P 500 Index. We may combine this finding of Bernanke and Kuttner (2005) with Williams (2011) estimate that QE was equivalent to a $0.75 \%$ drop in fed funds to say that a surprise announcement of QE was equivalent to a $3 \%$ increase in the S\&P 500 Index.

Rigobon and Sack (2004) articulate that it is difficult to estimate the response of asset prices to changes in monetary policy because of the endogeneity of policy decisions and the reality that interest rates, asset prices and numerous other macroeconomic variables are interrelated and react to numerous economic developments. These authors develop a new estimator that is based on the heteroscedasticity that exists in high frequency data and show that an increase in fed funds results in a decline in stock prices.

Since the introduction of QE several researchers have studied the impact of QE on asset prices. Rosa (2014) examines the impact of QE on asset prices using an event study methodology and confirms that the surprise component of QE has an economically large and statistically significant effect on asset prices. Moessner (2014) also finds that FOMC policy rate guidance as a tool at the zero lower bound leads to increases in equity prices. Bhar, Malliaris and Malliaris use a Markov regime switching methodology to confirm that QE impacts asset prices.

This selective bibliographic review confirms that monetary policy, fed funds policy, QE and Fed communications play an important role in affecting asset prices. Our contribution in this paper is to empirically examine the impact of QE on the stock market. QE has dominated the tools of Fed policy since the Global Financial Crisis since fed funds had reached the zero lower bound. Communication by the Fed continued to play an important role but its specific role is not distinguished in our study. The novel contribution of this paper is its methodological approach described in the next section. 


\section{Questions and Data}

In statistical procedures, a relationship is theorized and tested. Data mining procedures, in contrast, make no assumptions about an underlying distribution or form of the relationship. Data mining addresses the question of whether or not there is an observable pattern in a specific data set. Once patterns are identified, further data can be checked to see whether the pattern found continues on or changes. One of the foundational techniques in data mining is decision trees. Decision trees have been used in a number of financial studies recently. For example, using financial ratios, Delen et al (2013) apply four decision tree methodologies to determine firm performance. In a comprehensive literature review of various data mining techniques used to identify fraud, Ngai et al (2011) find that decision trees are one of the primary successful solutions to this problem. Charlot and Marimoutou (2014) investigate the relationships between the volatility and correlation of several series, including the S\&P 500, using a stochastic decision tree and find that the relationships of the series vary among regimes. A decision tree uses a dependent target variable as output and multiple input variables. Inputs can be quantitative or qualitative. The objective is, beginning with the entire data set to see if the data can be partitioned, in a step-wise fashion, into subsets which have a single value of the target. Han, Kamber and Pei (2012) give a detailed background on the development and structure of decision tree methodologies.

To investigate the impact of QE on equity prices, we consider two sample periods, January 2004 to September 2008 and October 2008 to November 2013. These correspond to a period of normal monetary policy prior to the financial crisis and the period on unconventional QE. We have collected daily data for the S\&P 500 Index from Yahoo.com and two longer term interest rates: the 10-Year Treasury Note and the 30-Year Mortgage Rate from FRED of the Saint Louis Fed. We also have weekly data of asset purchases that resulted from QE by the Fed. Beginning with December 2008, these grew on a much larger scale.

As discussed earlier, it is our purpose to study the impact of the quantitative easing on the stock market, as measured by the S\&P500 Index, using decision trees. We also wish to investigate whether stock market returns can be explained by longer term rates of both the 10

year T-Note and the Mortgage Rate. The Fed Assets capture the impact of quantitative easing. In addition to searching for relationships explaining the stock market's returns pre and post crisis, we also lag the independent variable data by one period to compute the one-period ahead forecast with the C5.0 decision tree methodology. Since the Fed has not articulated in great detail how QE was intended to contribute to its dual mandate of maximum employment and price stability, we do not formulate a speculative hypothesis because the profession has not formed a consensus on this issue. However, during the three rounds of QE, FOMC 
communications and speeches by members of the Board of Governors and Presidents of the Federal Reserve system conjectured that QE was intended to reduce long-term interest rates by increasing the value of Treasury securities and these lower interest rates were expected in turn to lift equity prices and housing values. In turn, it was conjectured that increases in wealth would increase consumption and investments, thus reducing unemployment. Expected inflation was deemed to remain low in view of low nominal long-term interest rates. Our decision tree methodology does not require the articulation of any specific scenario since none is currently available.

The data consists of four base inputs, Fed Assets, the S\&P 500, 10-year Treasury notes, and 30-year Mortgage Rates, and variables derived from them. Values for the ten-year notes, series DGS10, were downloaded, with daily values, from the Board of Governors of the Federal Reserve System site. The second series is WALCL. This was downloaded from FRED at the St Louis Fed, and consists of All Federal Reserve Banks - Total Assets, Eliminations from Consolidation, hereafter called fed assets. It is released once each week on Wednesday. Series three is the 30-Year Conventional Mortgage Rate from the Primary Mortgage Market Survey data provided by Freddie Mac. Values for this series are provided weekly on Thursday. The last series in the S\&P 500 adjusted close. This data was downloaded from finance.yahoo.com. These four series are named 10YrNote, FedAssets, WklyMortgageRate, and SP500 in the following analysis.

Because two of the series change on a weekly basis only, the data was matched using the following method: all values were taken as a snapshot of their value at close on Thursday. Since mortgage rates and the S\&P values occur daily, only the values on Thursdays were used. The 30-year mortgage value was used from the Thursday when it was released. The Federal Reserve Total Assets is announced only on each Wednesday, and is thus assumed to have the same value on Thursday as it had on the previous day. Thus, each series was reduced to its Thursday value and the series were matched on corresponding Thursdays. Once the data were reduced to weekly values, derived columns were created. These included the percent change of FedAssets from week to week, the percent change of the SP500, the direction of change from the previous week for each of the four base variables, and a shifted column containing next week's direction of movement of the S\&P 500. Figures 1 through 4 show graphs of each of the base variable values over the entire data set. 
Review of Economic Analysis 7 (2015) 135-156

Figure 1. Values of 30-year Mortgage Rates released weekly.

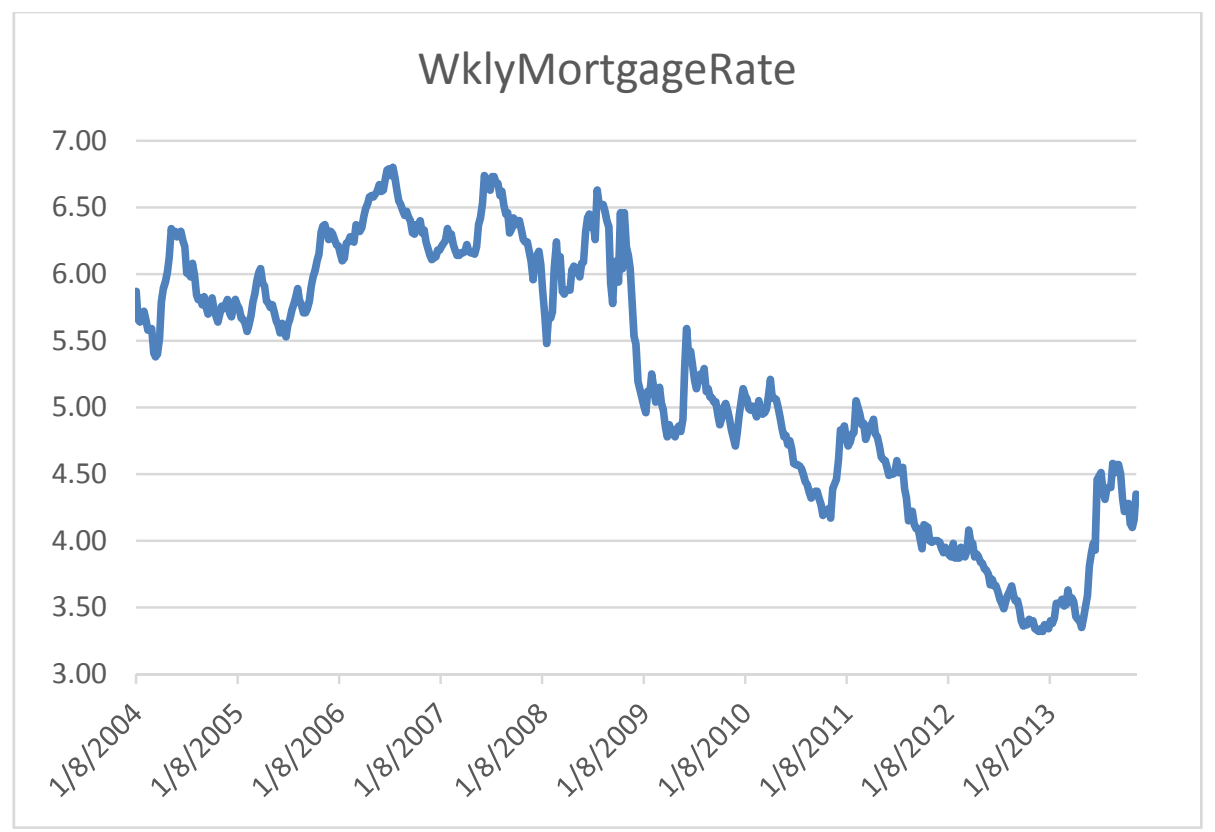

Figure 2. Values of 10-year notes.

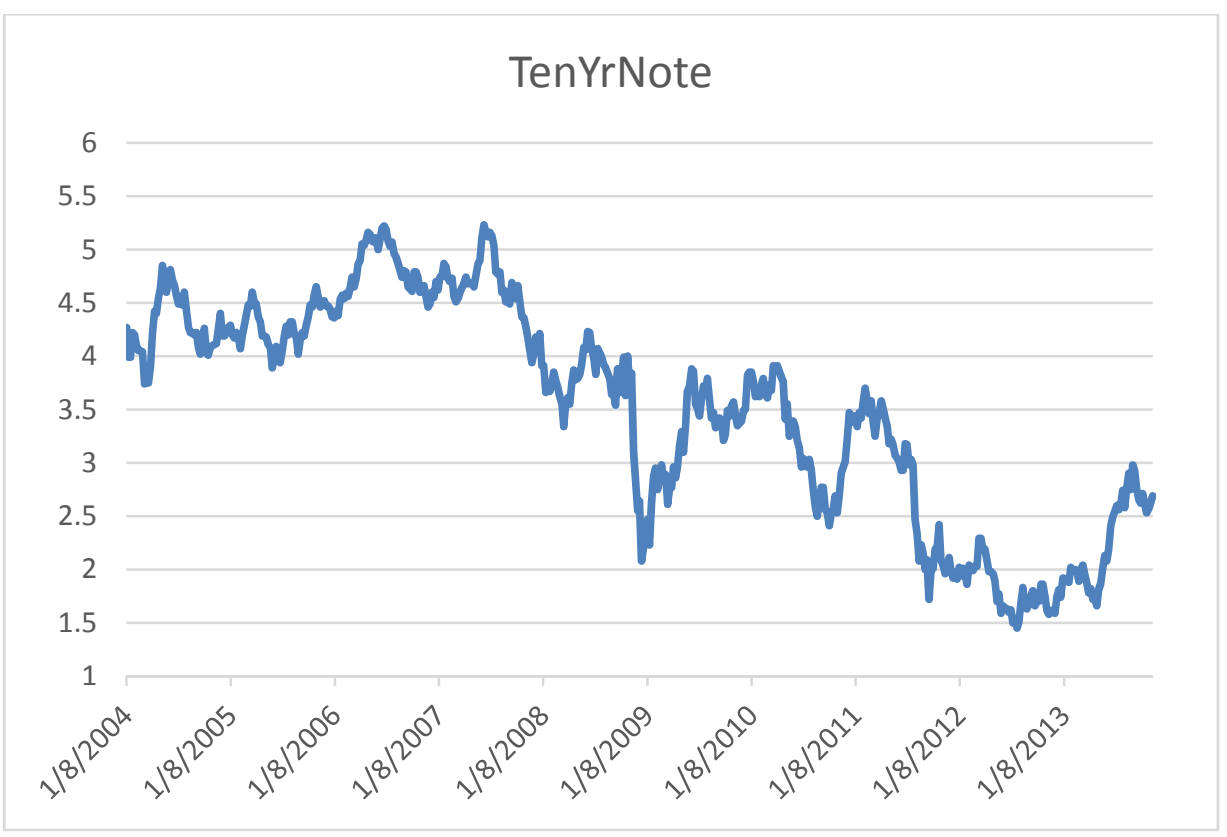


BHAR, MALLIARIS AND MALLIARIS Quantitative Easing and the U.S. Stock Market

Figure 3. Federal Reserve Total Assets

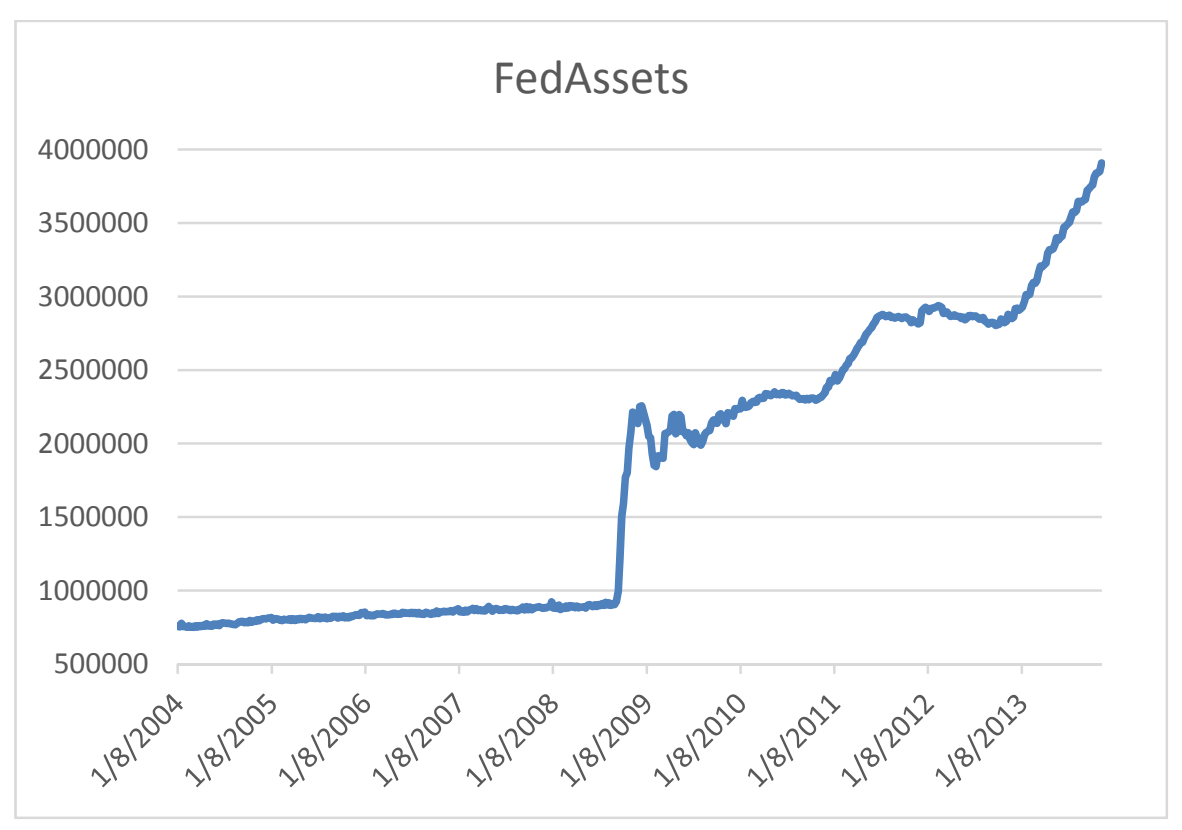

Figure 4. The S\&P 500 values on Thursdays.

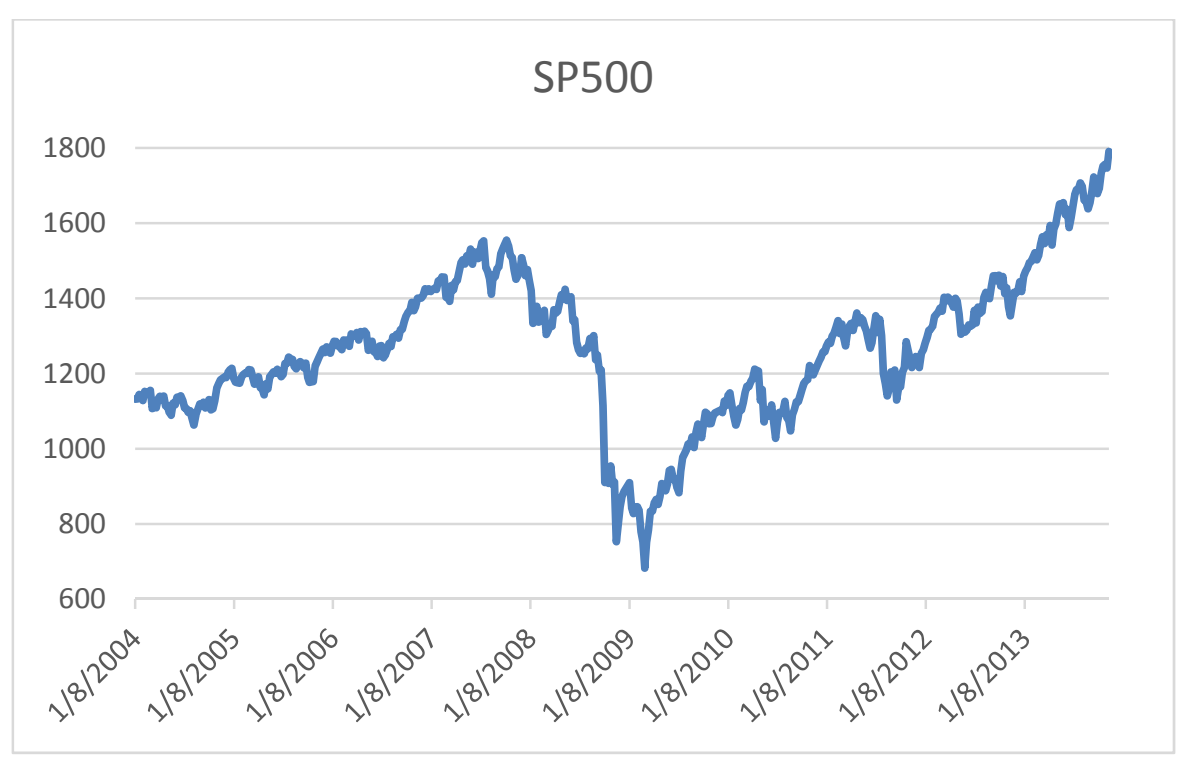


The matched data were divided into three sets. The first set, Before, consisted of data from January of 2004 through July of 2008. The second set, not used in model building, surrounded the crash and included August through November of 2008. The final set, After, consisted of data from December 2008 through mid-November 2013. Specific beginning and ending dates for each data set are shown in Table 1.

Table 1. Data sets used in decision tree construction and analysis.

\begin{tabular}{|l|r|r|}
\hline Set Name & First Date & Last Date \\
\hline \hline Before & $1 / 8 / 2004$ & $7 / 31 / 2008$ \\
\hline During & $8 / 7 / 2008$ & $11 / 20 / 2008$ \\
\hline After & $12 / 4 / 2008$ & $11 / 14 / 2013$ \\
\hline
\end{tabular}

The variables and the names used for each are indicated in Table 2. The 30-year mortgage rates that are released weekly are called WklyMortgageRate, the 10-year Treasury Notes are TenYrNote, the Federal Assets are FedAssets, and the S\&P 500 is denoted as SP500. The weekly percent changes in amount of the Federal Assets and in the S\&P 500 are designated as PChgFA and PChgSP, respectively. The remaining four variables refer to the direction each of the base variables moved from one week to the next. Finally, the target variable is the direction the S\&P 500 moved from the current week to the next.

The linear correlations between the numeric variables in the Before and After groupings are shown in Table 3 (non-numeric variables are not included here). Notice in particular that the relationships between the four base variables (shown as shaded in the cells) are all positive in the Before set. In the After set, we see that the correlations have turned negative in four combinations: MortRate-FedAssets, MortRate-SP500, 10YrNote-FedAssets, and 10YrNote-SP500. Also note that the correlation between FedAssets and SP500 has strengthened, as has that between MortRate and 10YrNote in the After data set. These shifts in relationships should be picked up by the decision tree model. That is, because the patterns in relationship among inputs have altered, we might expect the discovered patterns in the Before set to differ from the discovered patterns in the After set. 
BHAR, MALLIARIS AND MALLIARIS Quantitative Easing and the U.S. Stock Market

Table 2. Variables used in the C5.0 models

\begin{tabular}{|l|l|c|}
\hline Variable Name & \multicolumn{1}{|c|}{ Data } & Role \\
\hline \hline WklyMortgageRate & Continuous & Input \\
\hline TenYrNote & Continuous & Input \\
\hline FedAssets & Continuous & Input \\
\hline SP500 & Continuous & Input \\
\hline PChgFA & Continuous & Input \\
\hline PChgSP & Continuous & Input \\
\hline MortDir & Up or Down & Input \\
\hline NoteDir & Up or Down & Input \\
\hline FedDir & Up or Down & Input \\
\hline SPDir & Up or Down & Input \\
\hline SPDirTp1 & Up or Down & Target \\
\hline
\end{tabular}

The C5.0 Decision Tree model was used to classify the direction of the SP500 next week using the variable values from the previous week. The goal of the methodology is to split the data set up into final groups that have only one value of the target variable within the group. A group that has only one value of the target variable is said to be pure. The initial data set is held in a node called the root of the tree. Each variable is checked against data in this node to see how good a job it would do in splitting the data into subsets which are more single-valued on the target than the root node. In this case, the target is the direction of the S\&P [Up or Down] in the next period. The single variable which does the best job is selected for the first split. This is the initial branching of the tree and it results in new divisions of the original data into multiple nodes. Each of these new nodes is now inspected separately. If a node contains only one value of the target, the tree stops growing from that node. If the node has multiple target values, then each input variable is checked to see which one gives the best division of the data set into pieces that are more single-values on the target variable. That is, at a given node, the methodology asks which variable makes the most pure split, and applies it to that node. This process continues at each node until one of two events occurs: either the data in the node has only one value of the target, or there is no input variable that can be used to make a more pure split of the data. Different paths through the nodes may use different variables. All paths are not of equal length. A longer path signals that more variables were used in the search for pure target values based on the input variables. 
Table 3. Correlations of numeric variables in the Before and After data sets.

\begin{tabular}{|l|c|c|c|c|c|c|}
\hline Before & $\begin{array}{c}\text { Wkly } \\
\text { Mortgage } \\
\text { Rate }\end{array}$ & TenYrNote & FedAssets & SP500 & PChgFA & PChgSP \\
\hline \hline WklyMortgageRate & 1 & & & & & \\
\hline 10YrNote & 0.764 & 1 & & & & \\
\hline FedAssets & 0.498 & 0.034 & 1 & & & \\
\hline SP500 & 0.521 & 0.258 & 0.843 & 1 & & \\
\hline PChgFA & 0.026 & -0.021 & 0.116 & -0 & 1 & \\
\hline PChgSP & -0.017 & 0.059 & -0.058 & 0.058 & 0.062 & 1 \\
\hline
\end{tabular}

\begin{tabular}{|l|c|c|c|c|c|c|}
\hline After & $\begin{array}{l}\text { Wkly } \\
\text { Mortgage } \\
\text { Rate }\end{array}$ & 10YrNote & FedAssets & SP500 & PChgFA & PChgSP \\
\hline \hline WklyMortgageRate & 1 & & & & & \\
\hline TenYrNote & 0.903 & 1 & & & & \\
\hline FedAssets & -0.656 & -0.559 & 1 & & & \\
\hline SP500 & -0.662 & -0.465 & 0.933 & 1 & & \\
\hline PChgFA & -0.03 & 0.019 & 0.131 & 0.126 & 1 & \\
\hline PChgSP & 0.036 & 0.046 & -0.027 & 0.014 & 0.028 & 1 \\
\hline
\end{tabular}

When the tree has stopped growing, a set of rules is generated that uses the variables from the root to each end node in an If..Then structure to predict the value of the target. For example, a rule might say If Humidity $=$ High and Temperature $=$ Below Freezing Then Snow $=$ Yes. There will be one rule for each ending node. These rules can be checked for accuracy on the set on which the tree was trained, or on new data. Accuracy is determined by the proportion of times the target prediction is correct.

All models were developed and run in IBM's SPSS Modeler data mining software. Two models were developed, one for the Before data set, and one for the After data set. These models used the same inputs and the same target. Only the rows differed. Since the C5.0 model is data driven, it constructs a model that best explains the data set on which it was trained. This allows us to see the use (or not) of each of the variables within the model. In addition to developing models, Modeler also constructs a chart showing the relative importance of each input variable. 
BHAR, MALLIARIS AND MALLIARIS Quantitative Easing and the U.S. Stock Market

\section{Model Results}

The C5.0 decision tree model patterns are shown in Figure 5 for the Before and After data sets, and Table 4 tallies information about the number of levels and number of nodes at each level for the trees. We see that the Before tree has a total of 57 nodes with 8 levels under the root. The first split of the tree was on the variable SPDir. There are 29 nodes that are the end of a path. Each path corresponds to a rule for the decision tree, so this is equivalent to saying that this tree generates 29 rules. The shortest rule ends on the second level and is "If the SPDir $=\mathrm{D}$ and TenYrNote $<=3.870$ Then SPDirTp1 $=$ Up". The longest rules take 8 levels to complete, and there are 6 rules of this length. One of these is "If the SPDir = D and TenYrNote $>3.870$ and MortDir $=\mathrm{U}$ and NoteDir $=\mathrm{U}$ and TenYrNote $>4.220$ and SP500 $<=$ 1280.270 and FedDir $=\mathrm{U}$ and WklyMortgageRate $>6.130$ Then SPDirTp1 = D”. The level with the most nodes is level 5 . Of the 16 nodes on this level, 13 of them are the end of a path.

The diagram on the right part of Figure 5 illustrates the After decision tree. This tree has 8 levels under the root with a total of 51 nodes. The first split of the tree used the variable MortDir. The shortest paths end on level 3 with 4 rules of this length. The last level has 4 nodes indicating that there are 4 rules with 8 inputs in the If part of the rule. The widest level of this tree is the $6^{\text {th }}$ level where 7 paths end. One of the rules that ends on the $8^{\text {th }}$ level is: "If MortDir $=\mathrm{D}$ and SPDir $=\mathrm{U}$ and FedAssets $>2,325,300$ and FedAssets $<=2,884,750$ and FedDir $=\mathrm{U}$ and NoteDir $=\mathrm{U}$ and PChgSP $>0.599$ and PChgFA $<=0.062$ Then SPDirTp1 $=>$ U”.

Table 4. Levels and Nodes of Before and After decision trees.

\begin{tabular}{|c|c|c|c|c|}
\hline \multirow{2}{*}{ Level } & \multicolumn{2}{|c|}{ Before } & \multicolumn{2}{c|}{ After } \\
\cline { 2 - 5 } & \#Nodes & \#EndingNodes & \#Nodes & \#EndingNodes \\
\hline \hline Root & 1 & 0 & 1 & 0 \\
\hline 1 & 2 & 0 & 2 & 0 \\
\hline 2 & 4 & 1 & 4 & 0 \\
\hline 3 & 6 & 0 & 8 & 4 \\
\hline 4 & 12 & 4 & 8 & 4 \\
\hline 5 & 16 & 13 & 8 & 3 \\
\hline 6 & 6 & 4 & 10 & 7 \\
\hline 7 & 4 & 1 & 6 & 4 \\
\hline 8 & 6 & 6 & 4 & 4 \\
\hline Total & 57 & 29 & 51 & 26 \\
\hline \hline
\end{tabular}


Review of Economic Analysis 7 (2015) 135-156

Figure 5. Before and After decision trees.
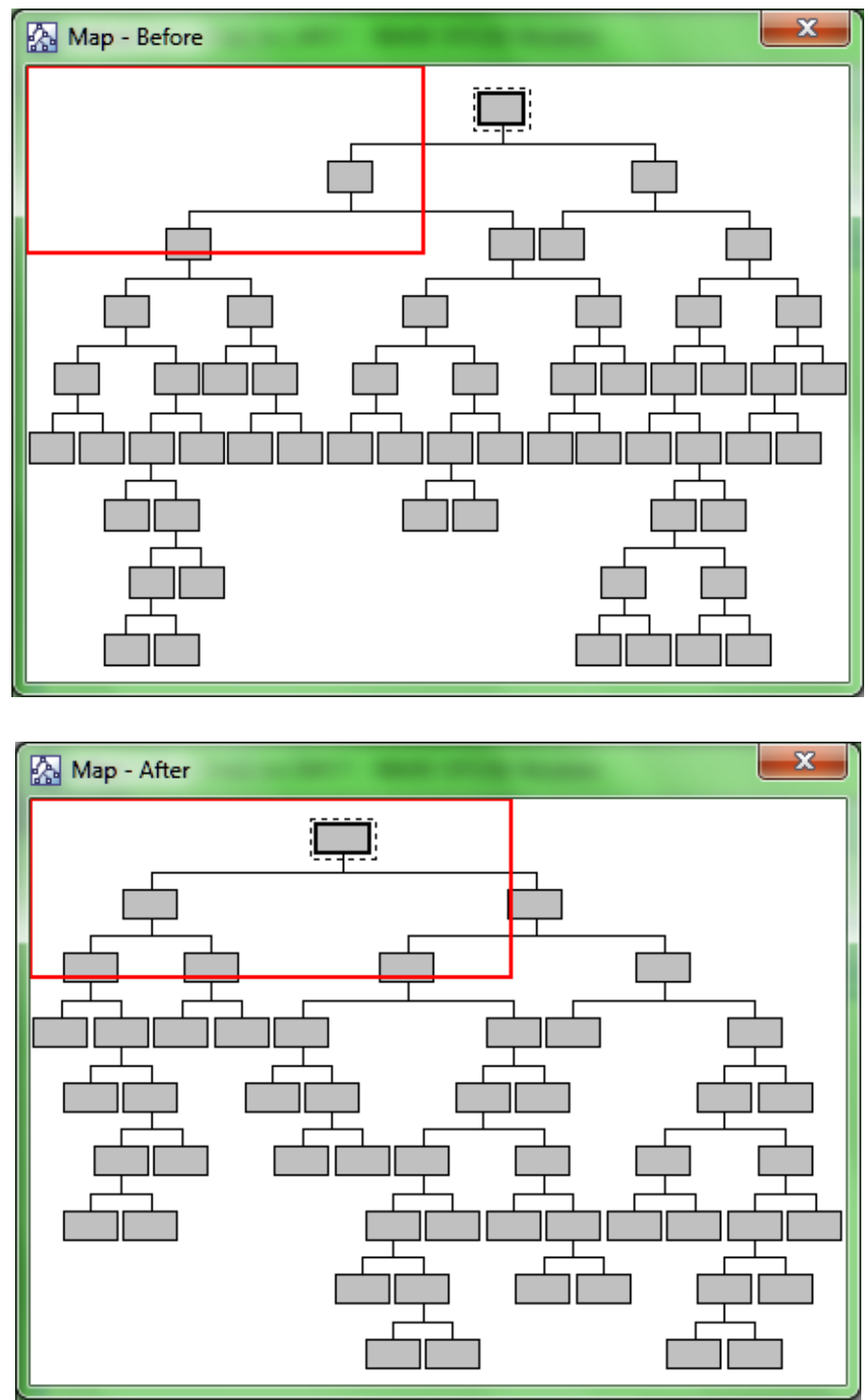

Variable importance is a relative number and all values sum to one. It is not related to accuracy, but is a measure of the influence a variable has on the model when it is determining the final value of the predicted target variable. In the Before data set, the four variables with the greatest impact on the forecast were TenYrNote, SPDir, NoteDir, and SP500. That is, two base values and two directional indicators were prominent in helping the model classify next 
week's move as up or down. Figure 6 shows a visual representation of these relative values generated by Modeler.

Since the variable used as a target is non-numeric, the judge of effectiveness of the model is a count of the number of correct and incorrect classifications. These are shown in Table 5. In this table, the column values are the forecasted classification of Down or Up, while the rows contain the actual directional value. We see that Down was forecasted 120 times $(90+$ 30) of which 90 were correct. For the Up direction, the model was correct 97 out of 114 times.

Figure 6. Variable importance in the Before data set.

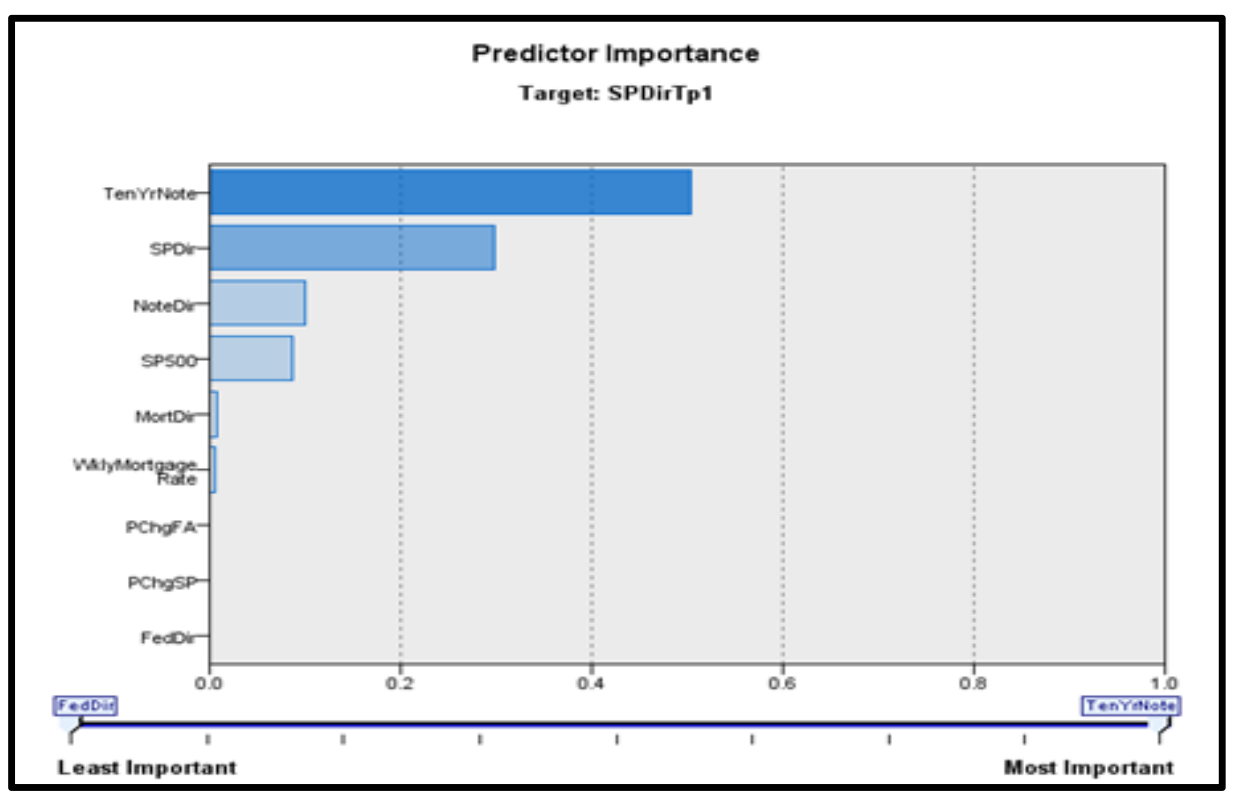

Table 5. Counts of correct and incorrect classifications in the Before data set.

\begin{tabular}{|l|l|l|l|}
\hline \multicolumn{4}{|c|}{ SC-SPDirTp1 } \\
\hline SPDirTp1 & & D & U \\
\hline D & Count & 90 & 17 \\
\hline & Column \% & 75.000 & 14.912 \\
\hline$U$ & Count & 30 & 97 \\
\hline & Column \% & 25.000 & 85.088 \\
\hline
\end{tabular}


The same set of variables, with different rows, was used to develop a C5.0 decision tree model for the After data set. The importance of the individual variables this time is shown here in Figure 7. The top four variables in this case were FedAssets, MortDir, PChgSP, and SPDir. We again have two numeric and two directional variables, but none of the top four in the After data set were in the top four in the Before data set.

For the count of correct directional classifications, the Table 6 shows that the Up forecasts were correct about the same percent of the time as in the Before data set, while the Down forecasts were over 10 percentage points better.

Figure 7. Variable importance in the After data set.

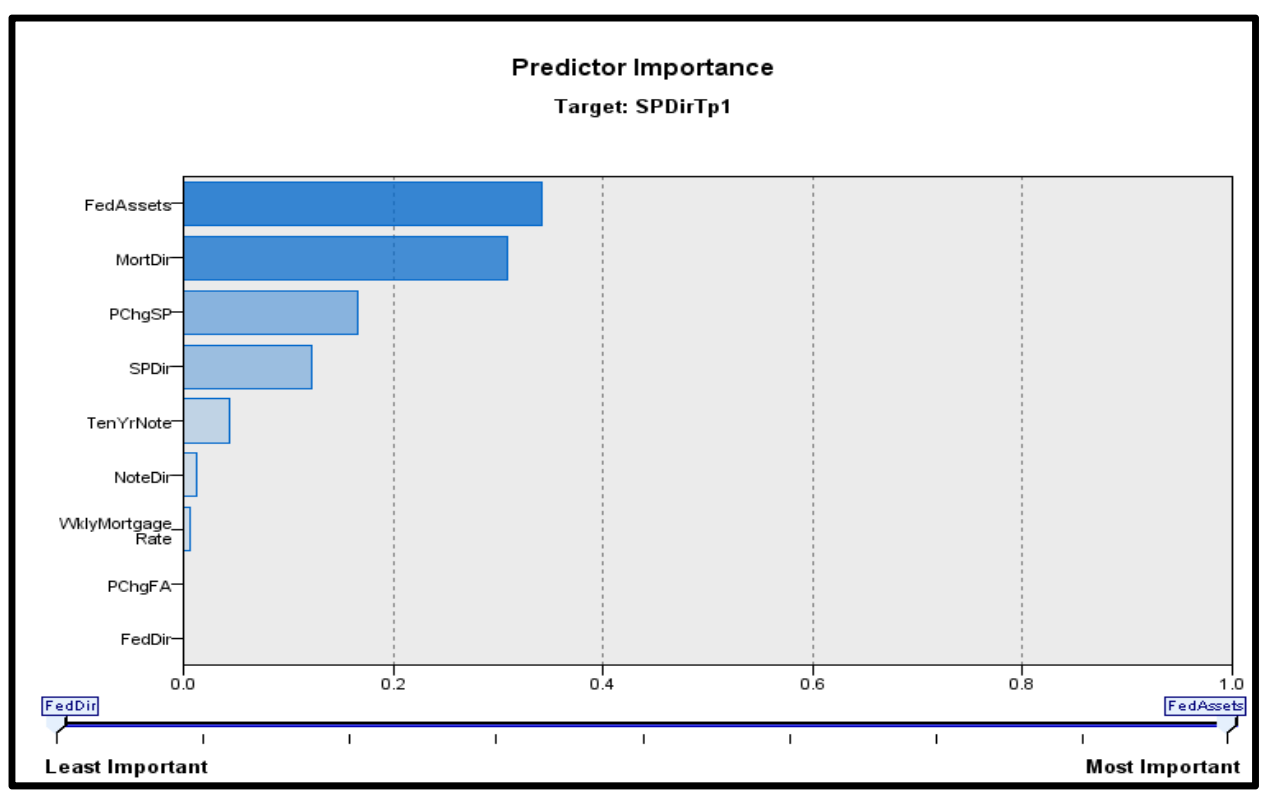

Table 6. Counts of correct and incorrect classifications in the After data set.

\begin{tabular}{|l|l|l|l|}
\hline \multicolumn{5}{|c|}{ SC-SPDirTp1 } \\
\hline SPDirTp1 & & D & U \\
\hline$D$ & Count & 68 & 28 \\
\hline & Column \% & 86.076 & 16.185 \\
\hline$U$ & Count & 11 & 145 \\
\hline & Column \% & 13.924 & 83.815 \\
\hline
\end{tabular}


As previously, the columns in Table 5 indicate the C5.0 model classification, while the rows show the actual direction of movement. We see that Down was predicted correctly 68 out of 79 times, and Up was correctly predicted 145 out of 173 times.

Table 7 lists the values for the relative variable importance of the Before and After data sets, along with the change per variable from the Before to the After data set. The variables are sorted by magnitude of change from positive, through zero, to negative. We see the greatest change in importance to the model in the increasing value of FedAssets and MortDir, and the decreasing value of the TenYrNote. Of special note is the increased importance of FedAssets, reflective of the impact of quantitative easing, from 0 Before to about a third of the weight in the After set. A slighter positive change occurred in PChgSP, and slight negative change in the SP500 and NoteDir. SPDir shows a moderate drop in influence. Showing almost no change in importance were WklyMortgageRate, FedDir, and PChgFA.

Given the shifts in variable impact for the models, it is also of interest to see whether the data also shifted significantly. Table 8 compares the data in the two sets in terms of the difference in the largest and smallest values for the numeric variables, and the proportions of values have Up and Down values for the non-numeric variables. We see in the numeric

Table 7. Relative variable importance, and change from Before to After.

\begin{tabular}{|l|c|c|c|}
\hline Nodes & $\begin{array}{c}\text { Before } \\
\text { Importance }\end{array}$ & $\begin{array}{c}\text { After } \\
\text { Importance }\end{array}$ & $\begin{array}{c}\text { Change in } \\
\text { Importance }\end{array}$ \\
\hline \hline FedAssets & 0.000 & 0.342 & 0.342 \\
\hline MortDir & 0.007 & 0.309 & 0.302 \\
\hline PChgSP & 0.000 & 0.165 & 0.165 \\
\hline WklyMortgageRate & 0.005 & 0.006 & 0.001 \\
\hline FedDir & 0.000 & 0.000 & 0.000 \\
\hline PChgFA & 0.000 & 0.000 & 0.000 \\
\hline SP500 & 0.087 & 0.000 & -0.087 \\
\hline NoteDir & 0.100 & 0.012 & -0.088 \\
\hline SPDir & 0.298 & 0.123 & -0.176 \\
\hline TenYrNote & 0.504 & 0.044 & -0.460 \\
\hline
\end{tabular}


Table 8. Comparison of variable values in Before and After data sets.

\begin{tabular}{|l|r|r|c|}
\hline Variable & \multicolumn{1}{|c|}{$\begin{array}{c}\text { Before } \\
\text { Max-Min }\end{array}$} & $\begin{array}{c}\text { After } \\
\text { Max-Min }\end{array}$ & $\begin{array}{c}\text { Percent } \\
\text { Change }\end{array}$ \\
\hline WklyMortgageRate & 1.42 & 2.27 & 59.9 \\
\hline TenYrNote & 1.89 & 2.46 & 30.2 \\
\hline FedAssets & 172,237 & $2,064,024$ & 1098.4 \\
\hline SP500 & 9.761 .18 & 1108.07 & 125.6 \\
\hline PChgSP & 8.032 & 21.666 & 122.0 \\
\hline PChgFA & Before & After & \\
\hline \hline & 0.517 & 0.619 & 19.7 \\
\hline \hline MortDir Down & 0.483 & 0.381 & -21.1 \\
\hline MortDir Up & 0.56 & 0.528 & -5.7 \\
\hline NoteDir Down & 0.44 & 0.472 & 7.3 \\
\hline NoteDir Up & 0.5 & 0.361 & -27.8 \\
\hline FedDir Down & 0.5 & 0.639 & 27.8 \\
\hline FedDir Up & 0.453 & 0.381 & -15.9 \\
\hline SPDir Down & 0.547 & 0.619 & 13.2 \\
\hline SPDir Up & & & \\
\hline
\end{tabular}

variables that there is a greater difference in the smallest and largest values assumed by each variable in the After data set. That is, the amount of variation within each of the numeric variables in the period following the crisis of 2008 increased significantly. Directional shifts were also apparent. The proportion of up and down days shifted least in Notes. The shift to the up direction in FedDir from 50\% to 64\% is not surprising, but we see this carried over to a greater proportion of up weeks in the SP500 and more down weeks in MortDir.

\section{Conclusions}

The Financial Crisis of 2007-09 caused the U.S. economy to experience a relatively long recession from December 2007 to June 2008. Both the U.S. government and the Federal Reserve undertook expansive fiscal and monetary policies to minimize both the severity and length of the recession. Most notably, the Federal Reserve initiated three rounds of unconventional monetary policies known as Quantitative Easing. These policies were intended to reduce long-term interest rates when the short term federal funds rates had reached the zero lower bound and could not become negative. Reducing longer term interest 
rates was not the terminal goal of the Fed that is driven by its mandate of maximum employment and price stability. It was postulated that QE would work via the portfolio channel to initiate repricing of financial assets. In particular, it was argued that the lowering of longer-term interest rates would help the stock market and thus the nation's wealth that in turn would reduce unemployment.

This paper carefully evaluates the pre-crisis and post-crisis literature on Fed policies and the stock market and concludes that the empirical evidence supports the hypothesis that monetary policy impacts the equity market. In view of the fact that the post-crisis monetary policy consisted of unconventional QE, which according to Bernanke (2015) called for great courage once the fed funds had reached the zero lower bound, we employ a decision tree methodology to study the impact of this courageous initiative. Specifically, it is our purpose to study the impact of Q1, Q2 and Q3 on the stock market as measured by the S\&P500 Index. To evaluate the impact of QE we compare the performance of the stock market before and after the crisis. QE did not exist prior to the crisis so the decision tree can quantify its influence. We considered two sample periods, January 2002 to September 2008 and October 2008 to November 2013. We collected daily data for the S\&P 500 Index from Yahoo.com and two longer term interest rates: the 10-Year Treasury Note and the 30-Year Mortgage Rate from FRED of the Saint Louis Fed. Beginning with December 2008 we also had weekly data of large scale asset purchases by the Fed.

Prior to the crisis we argue that stock market returns can be explained by longer term rates of both the 10 year T-Note and the Mortgage Rate. For the second and most recent sample we have the same dependent and independent variables and also the rate of change of the Fed's assets that are the result of QE. In addition to searching for relationships explaining the stock market's returns pre and post crisis, we also lagged the independent variable data by one period to compute the one-period ahead forecast with the C5.0 decision tree methodology.

In our analysis, the C5.0 Decision Tree model was used to classify the direction of the SP500 next week using the variable values from the previous week. The C5.0 method uses a nonnumeric target (next week’s S\&P 500 direction) and makes binary splits at each stage. All models were developed and run in IBM's SPSS Modeler data mining software. Two models were developed, one for data before the crash of 2008, and one after. These models used the same inputs and the same target. Only the rows differed. Since the C5.0 model is data driven, it constructed a model that best explained the data set on which it was trained. This allowed us to see the use (or not) of each of the variables within the model. Fed Assets have no impact on the stock market prior to the crisis as expected. Prior to the crisis the stock market was driven by longer-term interest rates. Post crisis, QE appears to be the main driver of the stock market. QE contributes analytically in the decision tree methodology in two ways: first by increasing Fed Assets that correlate significantly with the S\&P 500 Index and, second, by reducing the long-term interest rates which also lift stock prices. Thus, our paper 
concludes that Q1, Q2, and Q3 have contributed to the recovery of the U.S. stock market. This evidence is consistent with the existing literature that monetary policy impacts the stock market. While the pre-crisis monetary policy consisted of setting the fed funds rate, the influence of monetary policy in the post-crisis period derives from QE. Obviously, FOMC guidance contributes to the impact of monetary policy on stocks but it is not explicitly separated in this paper.

\section{References}

Bernanke, Ben (2012), Monetary Policy Since the Onset of the Crisis, Remarks at the Federal Reserve Bank of Kansas City Economic Symposium, Jackson Hole, Wyoming, August 31.

Bernanke, Ben (2015), The Courage to Act: A Memoir of a Crisis and its Aftermath, New York: W. W. Norton \& Company.

Bernanke, Ben and Kenneth Kuttner (2005), What Explains the Stock Market's Reaction to Federal Reserve Policy? The Journal of Finance, 60, pp. 1221-57.

Bhar, R., A.G. Malliaris and Mary Malliaris (2015), The Impact of Large-Scale Asset purchases on the S\&P 500 Index, Long-term Interest Rates and Unemployment, Applied Economics, 47, pp. 6010-6018.

Charlot, Philippe, Vêlayoudom Marimoutou (2014), On the Relationship Between the Prices Of Oil and the Precious Metals: Revisiting With a Multivariate Regime-Switching Decision Tree, Energy Economics, 44, pp. 456-467.

Chen, Han, Vasco Cúrdia, and Andrea Ferrero (2012), The Macroeconomic Effects of Large Scale Asset Purchase Programmes, The Economic Journal, 122(564), pp. F289-F315.

Delen, Dursun, Cemil Kuzey, and Ali Uyar (2013), Measuring Firm Performance Using Financial Ratios: A Decision Tree Approach, Expert Systems with Applications, 40(10), pp. 3970-3983.

Gagnon, Joseph, Matthew Raskin, Julie Remache, and Brian Sack (2011). The Financial Market Effects of the Federal Reserve's Large-Scale Asset Purchases, International Journal of Central Banking 7, pp. 3-43.

Hamilton, James, and Jing Cynthia Wu (2012), The Effectiveness of Alternative Monetary Policy Tools in a Zero Lower Bound Environment, Journal of Money, Credit, and Banking 44, pp. 3-46.

Han, Jiawei, Micheline Kamber, and Jian Pei (2012), Data Mining Concepts and Techniques, $3^{\text {rd }}$ Ed., Waltham, MA: Morgan Kaufmann Publishers.

Krishnamurthy, Arvind, and Annette Vissing-Jorgensen (2011), The Effects of Quantitative Easing on Interest Rates, Brookings Papers on Economic Activity 43(2), pp. 215-287. 
BHAR, MALLIARIS AND MALLIARIS Quantitative Easing and the U.S. Stock Market

Li, Canlin, and Min Wei (2013), Term Structure Modeling with Supply Factors and the Federal Reserve's Large-Scale Asset Purchase Programs, International Journal of Central Banking 9(1), pp. 3-39.

Moessner, Richhild. (2014), Effects of Explicit FOMC Policy-Rate Guidance on Equities and Risk Measures, Applied Economics, 46 (18), pp.2139-2153.

Ngai, E.W.T., Yong Hu, Y.H. Wong, Yijun Chen, and Xin Sun (2011). The Application Of

Data Mining Techniques In Financial Fraud Detection: A Classification Framework and An Academic Review Of Literature, Decision Support Systems, 50(3), pp. 559-569.

Rigobon, Roberto. And Brian Sack (2004), The Impact of Monetary Policy on Asset Prices, Journal of Monetary Economics, 51, 1553-75.

Rosa, C. (2012). How Unconventional are Large-Scale Asset Purchases? The Impact of Monetary Policy on Asset Prices. Federal Reserve Bank of New York Staff Reports No. 560, Federal Reserve Bank of New York, New York, NY.

Swanson, Eric (2011), Let's Twist Again: A High-Frequency Event-Study Analysis of Operation Twist and Its Implications for QE2, Brookings Papers on Economic Activity 42(1), pp. 151-207.

Thornton, D. (2014), QE: Is There a Portfolio Balance Effect? Federal Reserve Bank of St. Louis Review, Fist Quarter, pages 55-72.

Williams, John C. (2011), Unconventional Monetary Policy: Lessons from the Past Three Years FRBSF Economic Letter 2011-31 (October 3). 
Review of Economic Analysis 7 (2015) 135-156

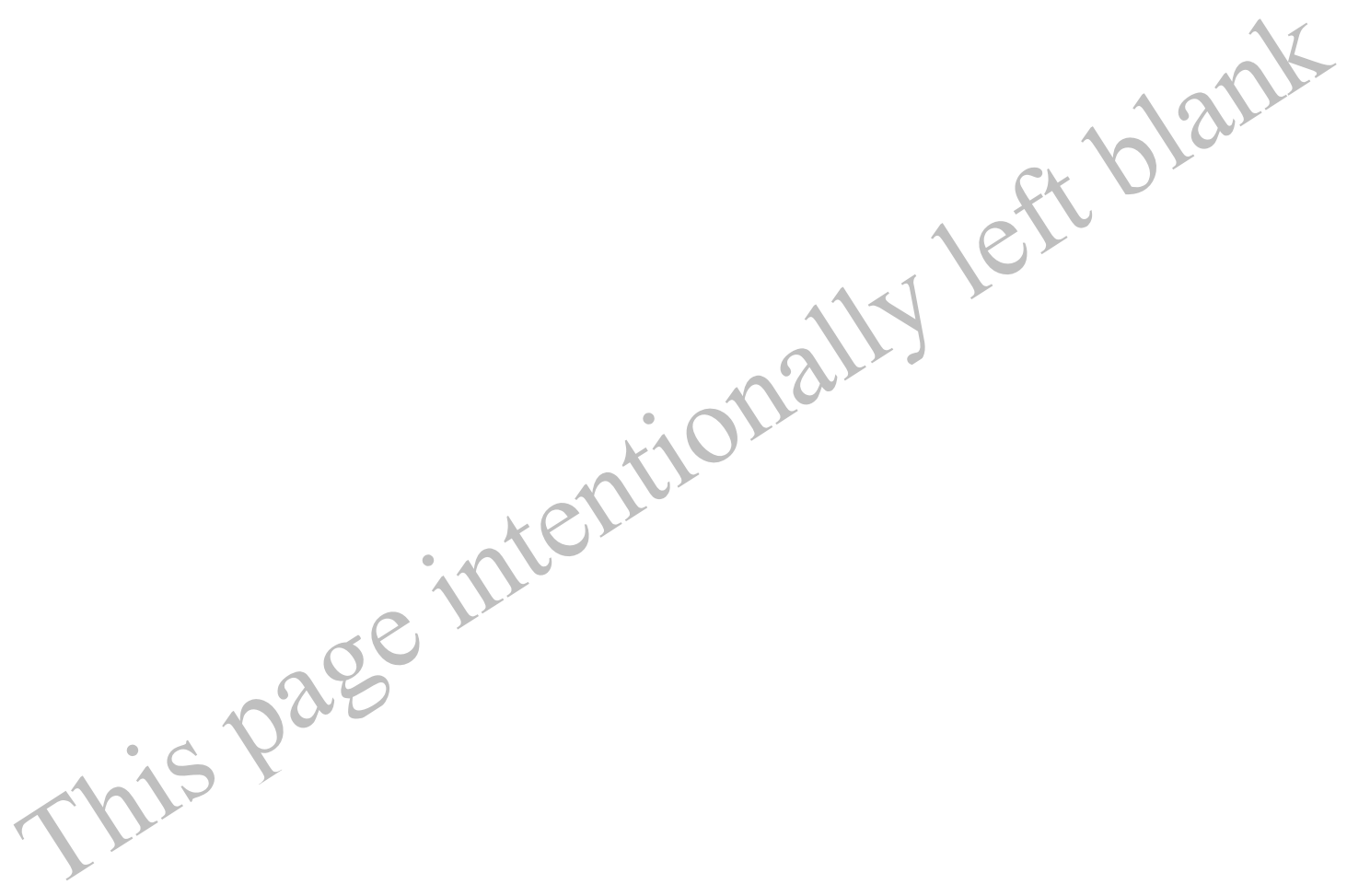

